\title{
Unemployment and the claimant count: October 2011
}

\author{
Author Name(s): Richard Clegg, Office for National Statistics
}

\begin{abstract}
Unemployment measures all people who meet the internationally agreed definition of unemployment. It is different from the claimant count, which measures only those people who are claiming unemployment-related benefits (Jobseeker's Allowance). The number of unemployed people in the UK is substantially higher than the claimant count. Not everyone who is unemployed is eligible for, or claims, Jobseeker's Allowance (JSA). Many unemployed people (especially women) are not eligible for JSA because they have a partner who is in work and/or because of their financial position. While most recipients of JSA would be classified as unemployed, some would fall into the "employed" or "economically inactive" categories.
\end{abstract}

\section{Unemployment}

Unemployment is measured using the Labour Force Survey and estimates are published for three month rolling average time periods. These are published once a month, moving the three month reference period forward by a month each time.

The definition of unemployment in the UK is consistent with the internationally agreed definition recommended by the International Labour Organisation (ILO) at the 13th International Conference of Labour Statisticians in October 1982.

Unemployed people in the UK are:

- without a job, have actively sought work in the last four weeks and are available to start work in the next two weeks or;

- out of work, have found a job and are waiting to start it in the next two weeks

Not all people out of work are classified as unemployed. Those who have not actively sought work in the last four weeks and/or are not available to start work in the next two weeks are classified as economically inactive, rather than unemployed, in accordance with ILO guidelines. 


\section{Claimant count}

The claimant count measures the number of people claiming unemployment-related benefits; since October 1996 this has been the number of people claiming Jobseeker's Allowance (JSA).

People who are out of work or working less than 16 hours a week on average may be eligible to claim JSA if they are:

- capable of working

- available for work

- actively seeking work

- below state pension age

Further information on eligibility for JSA is available on the Directgov website.

\section{Changes in unemployment and claimant count for those aged from 18 to 64}

The changes in the headline unemployment and claimant count estimates published in the Labour Market Statistical Bulletin are not directly comparable because:

- Unemployment estimates are averages for three-monthly time periods and the headline change is the change since the previous non-overlapping three-monthly time period. For example, estimates for April-June are compared with estimates for January-March rather than for MarchMay.

- The claimant count is a count of the number of people claiming Jobseeker's Allowance (JSA) on a particular day of the month and the headline change is the change since the previous month. It is more up to date than unemployment as it is derived from administrative data which can be collated quicker than survey data.

- Unemployment estimates include 16-17 year olds whereas the headline claimant count estimates do not include people below 18 years of age. 16-17 year olds are not usually able to claim JSA.

- There is no upper age limit on unemployment but people above state pension age are not usually eligible to claim JSA.

When the two series are compared for the same time periods (three-monthly averages), and for the same age groups (people aged 18 to 64), the movements in the two series over the latest quarter are fairly close. For this age group, between March-May and June-August 2011, unemployment increased by 106,000 and the claimant count increased by 81,000 . The chart below, and the associated spreadsheet, compares quarterly changes in unemployment and the claimant count for people aged from 18 to 64 for the last two years. 
Comparison of quarterly changes in unemployment and claimant count for those aged from 18 to 64 (United Kingdom, seasonally adjusted)

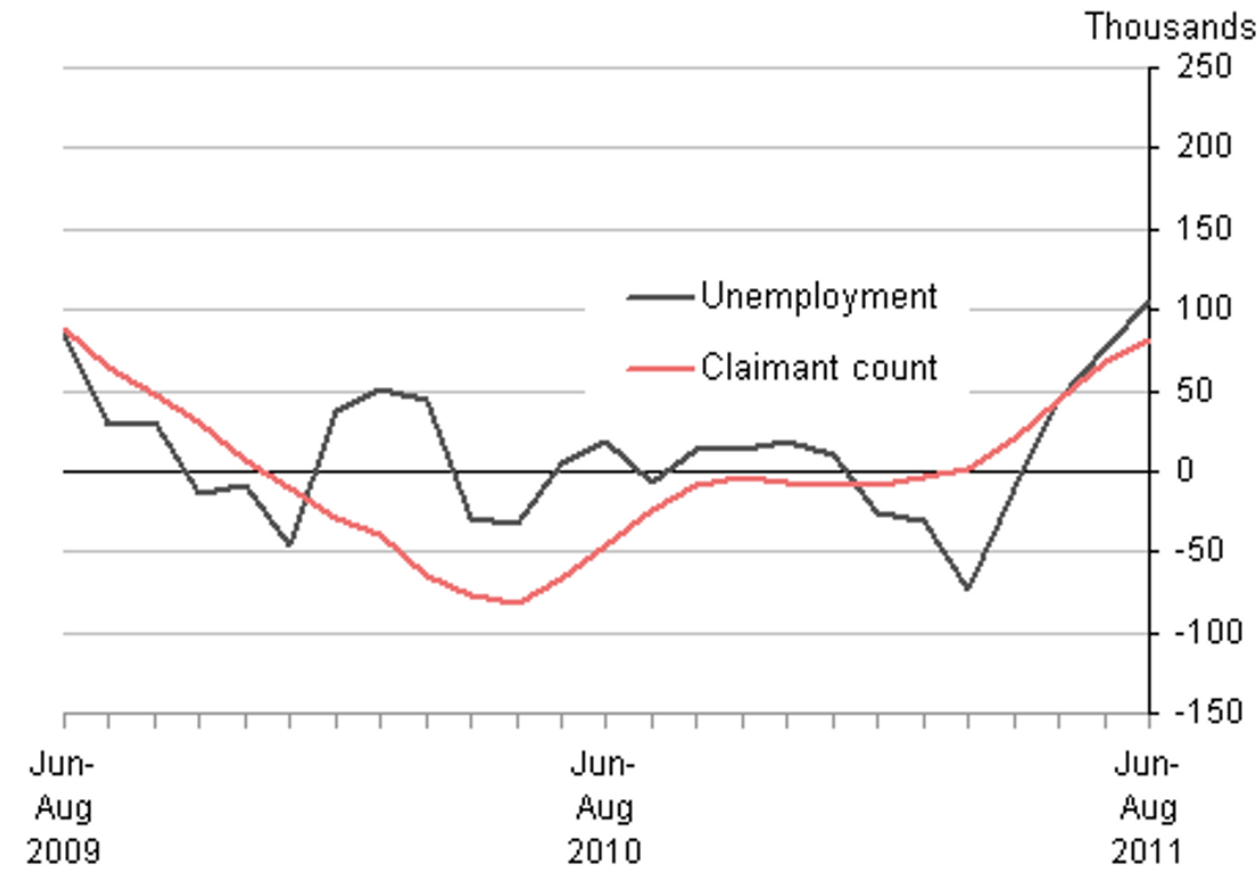

Source: Office for National Statistics

\section{Download chart}

XLS XLS format

$(60.4 \mathrm{~Kb})$ 